\title{
Pubic Lice in Facial Hair
}

\author{
Puravoor Jayasree, ${ }^{1}$ Feroze Kaliyadan, ${ }^{2}$ Karalikkattil T. Ashique ${ }^{3}$
}

1 Dermatology, Medical Trust Hospital, Cochin, Kerala, India

2 Dermatology, College of Medicine, King Faisal University, Saudi Arabia

3 Amanza Health Care, Nahas Skin Clinic, Perinthalmanna, Kerala, India

Key words: lice infestations, pruritus, hair, Phthirus, dermoscopy

Citation: Jayasree P, Kaliyadan F, Ashique KT. Pubic lice in facial hair. Dermatol Pract Concept. 2020;10(2):e2020042. DOI: https://doi. org/10.5826/dpc.1002a 42

Accepted: December 21, 2019; Published: April 20, 2020

Copyright: $@ 2020$ Jayasree et al. This is an open-access article distributed under the terms of the Creative Commons Attribution License, which permits unrestricted use, distribution, and reproduction in any medium, provided the original author and source are credited.

Funding: None.

Competing interests: The authors have no conflicts of interest to disclose.

Authorship: All authors have contributed significantly to this publication.

Corresponding author: Dr. Puravoor Jayasree MD, DNB, Consultant Dermatologist, Medical Trust Hospital, Cochin, Kerala, India, 682016. Email: jayasree5678@gmail.com

\section{Case Presentation}

A single male in his twenties presented with itching and a foreign body sensation in his moustache. He reported active, oral sexual contact with a female acquaintance 3 days prior to the onset of symptoms. Examination revealed yellowish deposits on the moustache and facial hair below the lower lip with erythema of the underlying skin (Figure 1A). On dermoscopy, crab-shaped parasites with broad bodies and thick claws were spotted clutching the hair shafts. Viable nits containing unhatched nymphs and empty translucent nit casings were also seen attached to proximal hair shafts (Figure 1B). Examination of the remaining hair-bearing skin including pubic area and eyelashes did not yield any findings. Thus a diagnosis of phthiriasis of the facial hair was made.

\section{Teaching Point}

Phthirus pubis or pubic louse can infest and survive in any hair-bearing skin [1]. Entomodermoscopy serves as a rapid diagnostic tool [2].

\section{References}

1. Chosidow O. Scabies and pediculosis. The Lancet. 2000;355(9206): 819-826.

2. Chuh A, Lee A, Wong W, Ooi C, Zawar V. Diagnosis of pediculosis pubis: a novel application of digital epiluminescence dermatoscopy. J Eur Acad Dermatol Venereol. 2007;21(6):837-838.

Figure 1. (A) Facial hair showing yellowish deposits and erythema of underlying skin. (B) Crabshaped pubic lice with thick claws grasping hair shafts along with brown (viable) and translucent (empty) nits seen on polarized dermoscopy.

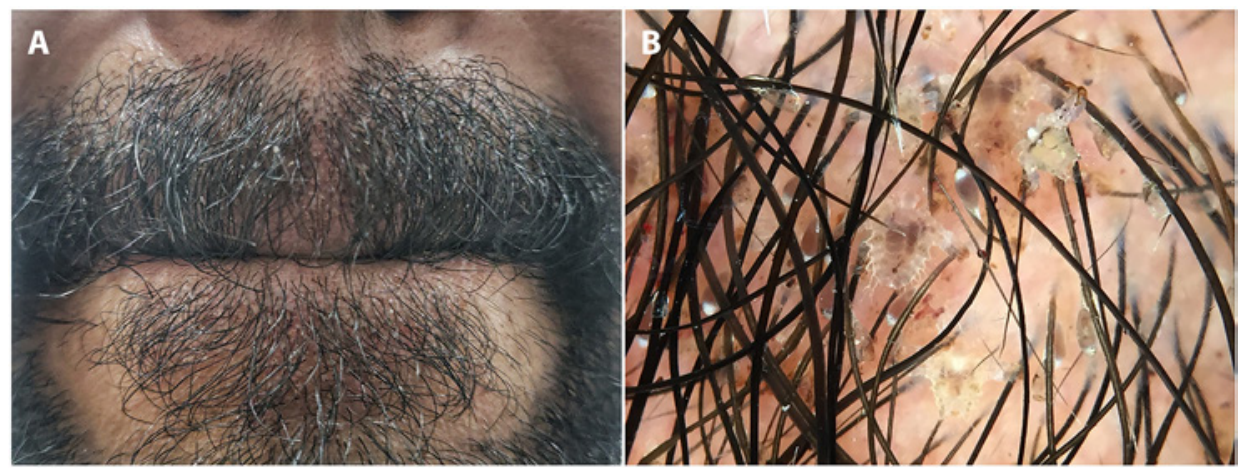

